Filología y Lingüística 46 (1): 306-309

Abril - Setiembre 2020

ISSN: 0377-628X / EISSN: 2215-2628

Doi: https://doi.org/10.15517/rfl.v46i1.41224

URL: https://revistas.ucr.ac.cr/index.php/filyling

\title{
Edgar Cota Torres y Mayela Vallejos Ramírez (Comps.). Fronteras globales. Globalización, literatura y frontera: Una visita a las travesías mundiales. Mexicali, Baja California: Editorial Artificios, 2019, 292 páginas
}

El volumen Fronteras globales. Globalización, literatura y frontera: Una visita a las travesías mundiales es la más reciente contribución a la colección New Borders / Nuevas Fronteras, una iniciativa de la Universidad Autónoma de Baja California en México y la University of Colorado at Colorado Springs en los Estados Unidos, iniciada en 2013, que ya cuenta con una docena de volúmenes de crítica, divulgación y creación, entre los que se encuentran En voz propia. In Their Own Voices: Entrevistas con narradores de la frontera México-Estados Unidos; Miradas convergentes. Ensayos sobre la narrativa México-Estados Unidos; Expedientes abiertos. Cuentos policiacos de la frontera México-Estados Unidos; y Futuros por cruzar. Cuentos de ciencia ficción de la frontera México-Estados Unidos.

Este nuevo volumen es fruto de la colaboración del doctor Edgar Cota Torres (University of Colorado at Colorado Springs) y la doctora Mayela Vallejos Ramírez (Colorado Mesa University), donde documentan desplazamientos humanos masivos que, por razones económicas, políticas, religiosas y hasta geológicas, dieron lugar a la formación de comunidades en otros territorios, con frecuencia en tensión y fricción con otros grupos. En la actualidad, la presencia y prevalencia de fenómenos migratorios afectan a todas las regiones del mundo "sea esto como país de origen, tránsito o destino" (11). Con frecuencia los migrantes pertenecen a "grupos marginados, olvidados, desfavorecidos por sus propios gobiernos" (11) y el proceso migratorio va acompañado de estigma, discriminación y violencia, lo que provoca crisis migratorias que dificultan aun más la experiencia de estas personas y sus oportunidades de supervivencia. Los ensayos incluidos en el volumen contemplan procesos migratorios y travesías variadas, enfocándose en particular en "tres grupos que durante el siglo XIX incursionaron hacia el Nuevo Mundo en busca de nuevos horizontes: chinos, judíos y vascos" (10). Las experiencias de estos grupos se presentan en 12 ensayos, desde una variedad de aproximaciones y perspectivas al fenómeno, que se pueden agrupar en cinco categorías: la experiencia de la comunidad judía en Argentina, la emigración colombiana a los Estados Unidos, la migración china a países latinoamericanos, la actual diáspora centroamericana en su periplo al Norte, y los estereotipos y falsas representaciones del migrante en los medios de comunicación.

El primer ensayo, de Suárez Meza, bajo el título "Proyecciones judeo-milenarias en la literatura de Birmajer. Sumas y restas identitarias en una sociedad globalizada en Tres mosqueteros" explora qué significa ser judío en Argentina a finales del siglo XX. El protagonista de la novela de 2001 es Javier Mossen, un joven argentino de origen judío quien, aunque no profundamente religioso o practicante del judaísmo, sí se identifica cultural y socialmente como judío. Javier, junto con los "tres mosqueteros" -Elías, Guidi y Benjamín-, presentan el mosaico de identidades que forman la comunidad judía en Argentina.

Los siguientes dos ensayos centran su atención en Colombia. Olsson en "Familia, fronteras y colonialidad global en Hot Sur" explora las relaciones familiares en el exilio y a 
través de fronteras en la novela de Laura Restrepo por medio de su protagonista María Paz. El ensayo analiza el concepto de "transnacionalización familiar" en tres categorías: "Autobiografía novelada desde la diferencia colonial" presenta los elementos metaficcionales de la novela que incluyen la voz narrativa, autorrepresentada como reportera y también escritora de la novela que estamos leyendo; "Separación y reunión a través de las fronteras: el silencio del pasado familiar" señala la importancia del espacio textual dedicado a la narración de la propia infancia y de la historia familiar, al mismo tiempo que destaca los silencios y los huecos -el de la memoria que falla, la madre que calla, y la hermana autista incapaz de verbalizar-; y "Búsqueda: más allá del sueño americano" que analiza la narrativa familiar con una lectura de la pertenencia espacial de los personajes migrantes a través del lente de género. Siguiendo con la experiencia colombiana, García Argüelles, por su parte, contribuye con un ensayo titulado "Migración y representación femenina en la literatura latinoamericana: voces y desplazamientos de Margarita Oropeza y Laura Restrepo" que detalla las transformaciones internas y externas de las protagonistas de dos novelas de las autoras colombianas: Después de la montaña (1992) de Oropeza y Hot Sur (2012) de Restrepo. Las protagonistas de estas dos novelas (Adelaida Quintero y María Paz) son emigrantes colombianas en los Estados Unidos, donde desarrollan una serie de habilidades de empoderamiento para sobrevivir en el modelo capitalista en que están inmersas, y así reinventarse en la ficción.

Los tres ensayos a continuación exploran la experiencia de las comunidades chinas en distintos puntos de América Latina. Montoya, Stiles y Wong se enfocan en la diáspora china a Cuba. Su estudio "La experiencia chino-cubana: una historia de migración, sacrificio y adaptabilidad", de corte histórico y etnográfico, detalla el contexto y las razones que provocaron la migración, y describe las dificultades de la integración en el entorno cubano y los retos para la asimilación. También incluye entrevistas a cubanos descendientes de aquellos inmigrantes, destacando los valiosos aportes de este grupo a la cultura y sociedad de la Cuba actual. A continuación, Chen Sham explora la migración china a Costa Rica en "Multiculturalidad y migraciones en Viaje al remoto Puntalín de Otto Apuy: de China a Costa Rica y viceversa" tal como aparece representada en la reciente novela (2016) de Apuy, artista plástico, poeta y narrador costarricense de origen chino. La novela es una saga que cuenta la historia colectiva de la inmigración china a través de un clan en particular, comenzando la historia con el viaje a América del patriarca Tai Chin Chen, y focalizándola por medio de su nieta Si Ling, quien conserva la memoria familiar y reproduce los testimonios orales de los miembros del clan. Un tercer ensayo detiene la mirada en la experiencia china en México. El estudio historiográfico de DeAlba, "La inmigración y el proceso de adaptación de los migrantes chinos en México", analiza las consecuencias legales que condicionaron la llegada de grupos procedentes de China a varias partes del territorio mexicano en las últimas décadas del siglo XIX, en particular a la frontera norte, debido al Acta de Exclusión promulgada en Estados Unidos que expulsó a los chinos de territorio norteamericano. DeAlba enfoca su estudio en el caso de la ciudad de Mexicali, donde favorecedoras leyes locales permitieron que la población china se multiplicara en un corto periodo de tiempo, permitiendo la preservación de la identidad cultural china de estos grupos inmigrantes y al mismo tiempo logrando su integración en la vida pública mexicana como ciudadanos.

El siguiente grupo de ensayos lidia con la difícil experiencia de los centroamericanos migrantes en su camino al Norte, en particular a su paso por territorio mexicano. En "La rapada: 
Masculinidad femenina y agencialismo distópico en La fila india de Antonio Ortuño", Villalobos propone una aproximación al texto de Ortuño a través de los estudios de género, analizando el concepto de "masculinidad femenina" por medio de un personaje femenino migrante, una mujer llamada Yein, que viaja con la cabeza rapada, desafiando las convenciones de género en cuanto a vestimenta y apariencia física de mujeres y hombres, lo que le da agencia y la empodera en un entorno peligroso y violento en que todos los individuos, especialmente mujeres y niños, son vulnerables y desvalidos, expuestos a las más terribles circunstancias que un ser humano puede encontrar. Zamora contribuye con su ensayo "La desmitificación del 'sueño americano' en Las murallas de Vides Méndez”, donde analiza la novela de 1998 del escritor guatemalteco. En esta novela, dos hombres guatemaltecos (Ramiro y el narrador, quien permanece anónimo) residentes en Nueva York luchan con conflictos internos de identidad y desarraigo, a la vez que intentan adaptarse a su situación vital en la gran urbe extranjera. Zamora sugiere que la novela de Vides propone un cuestionamiento de los egoístas valores individualistas que caracterizan el neoliberalismo.

Flores Merino en "Tras la pantalla: los migrantes como importantes emisarios de realidades menos evidentes y la errada representación mediática de lo ajeno" invita al lector a ser consciente del papel de los medios de comunicación en la percepción negativa del migrante y los procesos migratorios. Flores afirma que los migrantes son doblemente discriminados: por medio de leyes migratorias injustas, y por representaciones mediáticas estereotipadas y mal informadas que los pintan como criminales e intrusos que no pertenecen a la sociedad y nunca lograrán integrarse. Los estereotipos a que son sujetos los migrantes y las falsas representaciones que se hace de ellos en los medios de comunicación de masas también es un tema central en el ensayo de Santiago-Stommes, "Coming to America: Mass Media, Disillusionment and the American Dream in the Tales by Sandra Cisneros". Santiago problematiza el concepto del "sueño americano" con respecto a las mujeres en dos textos de la escritora mexicano-americana Sandra Cisneros. Mientras que el "sueño americano" promueve la idea de los Estados Unidos como la tierra prometida, llena de infinitas oportunidades, en la que cualquiera que esté dispuesto a luchar y trabajar duro puede abrirse camino sin importar de donde venga, en el caso de las protagonistas de Cisneros, las mujeres que pueblan los barrios de mayoría mexicana en las grandes ciudades del Norte, siguen sujetas al mismo sistema patriarcal con estrictas reglas en cuanto a los papeles de género y al lugar secundario de las mujeres en ese sistema. Por lo tanto, las personajes de Cisneros (Esperanza, Marin y Rafaela en The House on Mango Street y Cleófilas en Woman Hollering Creek) no tienen acceso a ninguna de las oportunidades que les permitiría alcanzar el sueño americano, y siguen sufriendo de opresión masculina en su entorno familiar y social, opresión perpetuada por la música en la radio, las telenovelas y anuncios publicitarios en la televisión, que les exigen permanecer en un espacio marginal y secundario, y las condiciona a una existencia limitada y carente de sueños.

Los dos últimos ensayos de la colección documentan, desde una perspectiva histórica, procesos migratorios claves en el desarrollo de Texas y del Oeste americano respectivamente. González Velázquez documenta la migración mexicana a la ciudad texana de San Antonio en su estudio "Laberintos de madera: andanzas por lo variopinto de la migración mexicana en San Antonio, Texas”. En sus precisas estadísticas, González incluye datos de individuos y grupos que migraron por razones económicas, en busca de mejores oportunidades de vida 
y trabajo, y asimismo incorpora información de otros grupos menos conocidos, como es el caso de individuos de más alto estatus económico en el campo empresarial, que huyen de la violencia y la extorsión en México. El estudio incluye entrevistas a una variedad de habitantes de la ciudad texana, las cuales nos of recen un colorido tejido de experiencias multiformes y variopintas con las que el lector puede discernir las profundas raíces mexicanas de esta ciudad del Norte. Por fin, Acker describe en "El periplo del pastor ovejero" el inicio y desarrollo de la industria ganadera de la oveja merina en el Oeste americano y su íntimo vínculo con los procesos migratorios que formaron a ese país. La oveja merina fue introducida por los españoles en el continente americano en el siglo XVI, y la industria ganadera conectada a este animal (enfocada principalmente en la producción de lana para manufacturar tejidos) está llena de abusos y violencia contra los pueblos indígenas nativos de las regiones que hoy pertenecen a los Estados Unidos y México. Esas gentes sufrieron bajo un sistema feudal controlado por hacendados y llevado a cabo por rancheros y pastores. A finales del siglo XIX llegan grupos vascos a la costa Oeste de los Estados Unidos y en seguida se establecen como ovejeros en estas regiones. En la primera mitad del siglo XX se crea el Programa Bracero, que permite la entrada temporal de trabajadores mexicanos. Más recientemente, el programa $\mathrm{H}-2$ ha traído ovejeros de Chile y Perú en contratos de tres años. Acker denuncia estos contratos como insuficientes e injustos, dominados por salarios bajos, largas jornadas de trabajo en malas condiciones, viviendas inadecuadas y numerosos abusos de derechos humanos básicos.

Los estudios incluidos en este volumen representan una magnífica adición a la ya formidable colección New Borders / Nuevas fronteras. Los compiladores del volumen, los doctores Cota y Vallejos, logran reunir 12 miradas diferentes al proceso migratorio, y así nos ofrecen un mosaico que, a través de sus fragmentos, nos ofrecen una imagen multifacética y polícroma de este fenómeno. Los ensayos presentan, desde una gran variedad de perspectivas, procesos, experiencias, autores y obras que dan vida a la larga, diversa, dolorosa y profundamente humana experiencia migratoria.

\author{
Josefa Lago Graña \\ University of Puget Sound \\ Tacoma, Washington, Estados Unidos
}

